Analysis

\title{
Non-consumptive values and optimal marine reserve switching
}

\author{
Satoshi Yamazaki ${ }^{\text {, }}$ R. Quentin Grafton ${ }^{\text {b,* }}$, Tom Kompas ${ }^{\text {b }}$ \\ a School of Economics and Finance, University of Tasmania, Australia \\ b Crawford School of Economics and Government, The Australian National University, Australia
}

\section{A R T I C L E I N F O}

\section{Article history:}

Received 15 January 2010

Received in revised form 7 June 2010

Accepted 9 July 2010

Available online 30 July 2010

\section{Keywords:}

Marine reserves

Stochastic control

Non-consumptive values

\begin{abstract}
A B S T R A C T
A bioeconomic model is constructed to analyze spatial harvesting and the effects of marine reserve "switching" between a "no-take" area and a harvested area while accounting for both harvesting/ consumptive and also non-consumptive values of the fishery. Using estimated parameters from the red throat emperor fishery from the Great Barrier Reef, simulations show that an optimal switching strategy can be preferred to a fixed reserve regime, but is dependent on spillovers from reserves to harvested areas, the nature of shocks to the environment, the size of the non-consumptive values and how they change with the biomass, and the sensitivity of profits to the harvest and biomass. Importantly, the results show that how non-consumptive values change with the size of the fishery substantially affects both the returns from switching and the optimal closure time.
\end{abstract}

(c) 2010 Elsevier B.V. All rights reserved.

\section{Introduction}

In the last two decades the use of marine reserves has received increased attention as a strategy to solve management failures in fisheries. There is theoretical and some empirical evidence of the potential biological and socio-economic benefits from closing a fishing ground. ${ }^{1}$ For instance, reserves may: 1 ) increase population abundance and improve habitat quality (e.g., Halpern, 2003); 2) generate positive spillovers of larvae and/or fish from the reserve to harvested populations (e.g., McClanahan and Mangi, 2000; Roberts et al., 2001); 3) reduce the variation in biomass and catch (e.g., Conrad, 1999; Mangel, 2000); 4) enhance tourism and recreational activities (e.g., Bhat, 2003) and other non-consumptive benefits (Wielgus et al., 2008); 5) act as a hedge against recruitment failure and unexpected variations in marine environments (e.g., Lauck et al. 1998; Grafton et al., 2006) and 6) increase catches/economic profits if targeted species are overexploited (Pezzey et al., 2000) or the harvesting cost is highly density dependent (White et al., 2008). By contrast, the potential costs of closing a fishing ground include 1) decrease in area available for fishing; 2) increase in harvesting costs and institutional costs and 3 ) increase in congestion of fishing effort (e.g., Hannesson, 1998; Carter, 2003). These benefits and costs are highly dependent on marine reserve design.

We explore the problem of spatial harvesting and optimal marine reserve design where the location of a "no-take" area is temporally switched. We derive the marginal equilibrium conditions of spatial

\footnotetext{
* Corresponding author. Tel.: +612 6125 6558; fax: +6126125 5570 .

E-mail address: quentin.grafton@anu.edu.au (R.Q. Grafton).

${ }^{1}$ There are a large number of previous studies on marine reserves. Comprehensive literature reviews are provided by for example Guénette et al. (1998), Hilborn et al. (2004) and Grafton et al. (2005).
}

harvesting and optimal closure of a fishing ground with both consumptive and non-consumptive values. ${ }^{2} \mathrm{~A}$ bioeconomic model is then constructed to analyze the effects of marine reserve "switching" between a "no-take" area and a harvested area. ${ }^{3}$ Using this model, we compare the harvest and biomass associated with a fixed reserve and those associated with a reserve that can be optimally transferred into a harvested area. Given that reserves are frequently established for non-consumptive values, such as maintaining biodiversity (Allison et al., 1998; Worm et al., 2006), we investigate the effect of different non-consumptive value functions on the optimal switching regime. Taking into account the non-consumptive values of the fishery is an important issue for optimal marine reserve design. Until now these values have not been modeled in conjunction with consumptive values in the switching policies for marine reserves. ${ }^{4}$

Switching the location of a reserve is expected to yield different economic and biological results from a permanently fixed reserve. By optimally locating a "no-take" area over time, the reserve switching strategy can adapt to wider range of possible outcomes than the fixed

\footnotetext{
${ }^{2}$ Non-consumptive values considered in this paper are directly related to the size of fish stocks and these values include benefits from recreational activities (e.g., scuba diving) and biological conservation (Carter, 2003).

${ }^{3}$ There are few but important previous studies looking at temporary fishing closures. For example see Hilborn and Walters (1992), Guénette et al. (1998) and Costello and Polasky (2008). Costello and Polasky (2004) also study the dynamic site selection problem of protecting biodiversity but not in the context of marine reserves.

4 Several studies estimate the non-market value of marine reserves by incorporating non-market valuation methods. Bhat (2003), for example, estimates that reserveinduced reef quality improvements could increase the value of a reserve in Florida Keys in the U.S. by 69\%. Kragt et al. (2009) estimate a recreational demand curve in the Great Barrier Reef and show that the welfare loss due to environmental degradation is substantial.
} 
reserve regime, especially when there is large uncertainty in environment.

The contribution of this paper is to evaluate: (1) the payoffs of optimal marine reserve switching under uncertainty and (2) the effect of non-consumptive value functions on the optimal switching rule. Section 2 develops a bioeconomic model of spatial harvesting strategy, incorporating both the harvesting and non-consumptive value of the fishery. Section 3 extends the modeling to construct a bioeconomic model of marine reserve switching where the location of a "no-take" area is optimally chosen. The model is applied to the red throat emperor fishery of the Great Barrier Reef. Section 4 describes this fishery and simulates and contrasts the economic and biological outcomes of different policy scenarios. Section 5 explicitly evaluates the effects of three different non-consumptive value functions on optimal switching while Section 6 concludes.

\section{Spatial Harvesting Strategy and Marginal Equilibrium Conditions}

\subsection{Conceptual Model}

Time is discrete, indexed by $t=\{0,1,2, \ldots\}$. Space is also discrete with $n$ patches that represent a metapopulation and is indexed by $i$, $j \in N$ where $N=\{1,2, \ldots n\}$. We assume that the distance between patches is identical and fixed and each patch has the constant carrying capacity. The various forms of dispersal processes between patches $i$ and $j$ are captured by the transfer function $T\left(x_{t}^{i}, x_{t}^{j}\right)$ where $x_{t}^{i} \geq 0$ is the fish stock in patch $i$ at time $t$.

The population dynamics in each patch are modeled as:

$x_{t+1}^{i}=x_{t}^{i}+G\left(x_{t}^{i}\right)+\sum_{j}^{i \neq j} T\left(x_{t}^{i}, x_{t}^{j}\right)-h_{t}^{i}$

where, $G\left(x_{t}^{i}\right)$ is the growth function and $h_{t}^{i}$ is the harvest. We assume that the fish flow from $i$ to $j$ depends on the relative density of the population between the two patches and $T_{x_{t}^{i}}<0$ and $T_{x_{t}^{j}}>0$ in patch $i^{5}$ The density dependent spillover is consistent with evidence from previous studies (e.g., Abesamis and Russ 2005). We also assume that the net fish migration between patches $i$ and $j$ is symmetric such that $T\left(x_{t}^{i}, x_{t}^{j}\right)$ in patch $i$ is equal to $-T\left(x_{t}^{j}, x_{t}^{i}\right)$ in patch $j$.

The regulator aims to set a harvest limit in each patch so as to maximize the discounted economic value of a fishery. Assuming that the regulator takes into account both the value of harvesting and nonconsumptive value, the regulator's optimization problem is specified as:

$$
\begin{array}{r}
\max _{\left\{h^{i}\right\}_{0}^{j} j_{0}} \sum_{t=0}^{\infty} \beta^{t} \sum_{i=1}^{n}\left(R^{i}\left(h_{t}^{i}, x_{t}^{i}\right)+N C^{i}\left(x_{t}^{i}\right)\right) \\
\text { subject to } x_{t+1}^{i}=x_{t}^{i}+G\left(x_{t}^{i}\right)+\sum_{j}^{i \neq j} T\left(x_{t}^{i}, x_{t}^{j}\right)-h_{t}^{i}
\end{array}
$$$$
x_{0}^{i} \text { given for all } i
$$

where $R^{i}(\cdot)$ is the patch specific net profit function from exploiting the fish stock and $\beta=1 /(1+\rho)$ is the discount factor where $\rho$ is the discount rate. We assume $R_{h_{t}^{i}}^{i}>0$ and $R_{x_{t}^{i}}^{i}>0$ and that the second-order conditions of the maximization problem are satisfied. The second inequality implies that the higher the population size, the lower the harvesting cost (i.e., stock effect). If there is no stock effect, then $R_{t}^{i}=R^{i}\left(h_{t}^{i}\right)$ and $R_{x_{t}^{i}}^{i}=0$. The function, $N C^{i}(\cdot)$, is the non-consumptive value of the fish stocks in patch $i$ and we assume $N C_{x_{t}}^{i}>0$. The nonconsumptive values considered here include the benefits of enhancing

\footnotetext{
${ }^{5}$ A function with a subscript denotes a partial derivative with respect to the subscripted variable other than $t$.
}

recreational activities (e.g., scuba diving) and biological conservation (Carter, 2003).

The Lagrangian function for this problem is:

$\mathcal{L}=\sum_{t=0}^{\infty} \beta^{t}\left[\sum_{i=1}^{n}\left[R^{i}\left(h_{t}^{i}, x_{t}^{i}\right)+N C\left(x_{t}^{i}\right)+\lambda_{t}^{i}\left(x_{t}^{i}+G\left(x_{t}^{i}\right)+\sum_{j}^{i \neq j} T\left(x_{t}^{i}, x_{t}^{j}\right)-h_{t}^{i}-x_{t+1}^{i}\right)\right]\right]$

where $\lambda_{t}^{i}$ is the Lagrangian multiplier. The first-order conditions for the problem are given by:

$$
\begin{aligned}
& R_{h_{t}^{i}}^{i}=\lambda_{t}^{i} \\
& \beta\left(R_{x_{t+1}^{i}}^{i}+N C_{x_{t+1}^{i}}^{i}+\lambda_{t+1}^{i}\left(1+G_{x_{t+1}^{i}}+\sum_{j}^{i \neq j} T_{x_{t+1}^{i}}\right)-\sum_{j}^{i \neq j} \lambda_{t+1}^{j} T_{x_{t+1}^{i}}\right)=\lambda_{t}^{i} \text {; and } \\
& x_{t+1}^{i}=x_{t}^{i}+G\left(x_{t}^{i}\right)+\sum_{j}^{i \neq j} T\left(x_{t}^{i}, x_{t}^{j}\right)-h_{t}^{i} \text { for all } i .
\end{aligned}
$$

At the steady-state where $x_{t}^{i}=x_{t+1}^{i} \equiv \bar{x}^{i}$ and $h_{t}^{i}=h_{t+1}^{i} \equiv \bar{h}^{i}$ the harvest limit in patch $i$ is chosen to satisfy the following marginal equilibrium conditions:

$$
\begin{aligned}
& \rho=G_{\bar{x}^{i}}+\frac{R_{\bar{x}^{i}}+N C_{\bar{x}^{i}}}{R_{\bar{h}^{i}}}+\frac{\sum_{j}^{i \neq j}\left(R_{\bar{h}^{i}}-R_{\bar{h}^{j}}\right) T_{\bar{x}^{i}}}{R_{\bar{h}^{i}}} \\
& \bar{h}^{i}=G\left(\bar{x}^{i}\right)+\sum_{j}^{i \neq j} T\left(\bar{x}^{i}, \bar{x}^{j}\right) \text { for all } i
\end{aligned}
$$

Eq. (4) equates the marginal cost and marginal benefit of delaying the harvest to the next period for all patches, while accounting for both consumptive and non-consumptive values. This condition is analogous to the Hartman rotation (Hartman, 1976) in forestry that considers both timber and non-timber benefits. ${ }^{6}$ The term, $\rho$, on the left hand side of Eq. (4) is the discount rate which represents the marginal cost of delaying the harvest to the next period. The right hand side of the equation is the marginal benefit of delaying the harvest and consists of three parts. The first term, $G_{\bar{x}^{i}}$, is the direct benefit of delaying the harvest due to the increase in fish stocks. The increase in fish stocks also decreases the harvesting cost due to the stock effect and this is captured by the second term, $\left(R_{\bar{x}^{i}}+N C_{\bar{x}^{i}}\right) / R_{\bar{h}^{i}}$ (i.e., marginal stock effect). The last term, $\sum_{j}^{i \neq j}\left(R_{\bar{h}^{i}}-R_{\bar{h}^{j}}\right) T_{\bar{x}^{i}} / R_{\bar{h}^{i}}$, represents the impact of delaying the harvest on fish spillover (i.e., marginal spillover effect). Therefore, the sign and relative size of each term determine the marginal benefit of delaying the harvest to the next period.

The term, $G_{\bar{x}}$, is positive or negative depending on the size of population and the second term, $\left(R_{\bar{x}^{i}}+N C_{\bar{x}^{i}}\right) / R_{\bar{h}^{i}}$ is always positive, but the sign of the third term $\sum_{j}^{i \neq j}\left(R_{\bar{h}^{i}}-R_{\bar{h}^{j}}\right) T_{\bar{x}^{i}} / R_{\bar{h}^{i}}$ is ambiguous and depends on the relative profitability of the harvest between patches. For instance, if an additional harvest at patch $i$ is globally less profitable, $R_{\bar{h}^{i}}<R_{\bar{h}^{j}}$ for all $j$, then the marginal spillover effect is positive. Therefore, the marginal benefit of delaying the harvest in patch $i$ is greater than when the fish population is immobile. This is because when there is fish spillover it is economically profitable to wait until the fish migrates from patch $i$ to its adjacent patches.

Accounting for the non-consumptive value of the fish stocks increases the marginal stock effect and, thus, the benefit of delaying the

\footnotetext{
${ }^{6}$ If the fish population is immobile and no consumptive value is accounted for, the equilibrium condition becomes $\rho=G_{\bar{x}^{i}}+R_{\bar{x}^{i}} / R_{\bar{h}^{i}}$ for all $i$, which is equivalent to that shown in Clark and Munro (1975).
} 
harvest. This is because an increase in fish biomass not only decreases the harvesting cost, but it also increases the non-consumptive value of the fishery. As a result, the benefit of delaying the harvest to the next period is greater when the non-consumptive value is considered.

\subsection{Spatial Harvesting, Marine Reserves and Non-consumptive Values}

The marginal equilibrium conditions (4) and (5) suggest that when the marginal benefit of delaying the harvest is sufficiently large in patch $i$, the temporal or permanent closure of patch $i$ is an optimal harvesting strategy. ${ }^{7}$ In particular, when patch i's marginal harvesting value is relatively less than the other patches and the fish migrate from patch $i$ (patch $i$ is a source), its closure is likely to be optimal. This is because the spillover benefit from patch $i$ to adjacent patches is greater than the harvesting benefit in patch $i$. If there are no fish spillovers at all, the closure of any fishing ground as a "no-take" area is not economically beneficial. With respect to the non-consumptive value of the fishery, the marginal equilibrium conditions (4) and (5) suggest that the optimal closure of a fishing ground is more likely to happen when the non-consumptive value is positive and accounted for by decision makers.

While the marginal equilibrium conditions (4) and (5) provide useful information to decide which fishing ground should be closed as a "no-take" area, it is still not clear whether the area should be closed permanently or "switched" and re-exploited over time. In the following section we will explore this issue, and further, analyze how the non-consumptive value of the fishery affects the optimal reserve switching rule.

\section{Optimal Marine Reserve Switching and Non-consumptive Values}

We construct a bioeconomic model of optimal marine reserve switching, accounting for both the net harvesting profit and the nonconsumptive value of the fishery. For tractability and ease of interpretation of the results, we consider a case with two populations; harvested and reserve populations $\left(x^{H}\right.$ and $\left.x^{R}\right)$. We also assume the policy regime is fixed. Thus, one of the patches is always closed as a "no-take" area and the other is open. The location of the "no take" area is thus a control variable and optimally chosen in each period. This assumption allows us to explicitly compare the reserve switching with a spatially fixed reserve regime. ${ }^{8}$

The population dynamics for the harvested population, $x^{H}$, and reserve population, $x^{R}$, are respectively specified as:

$$
\begin{aligned}
& x_{t+1}^{H}=x_{t}^{H}-z_{t}^{S} x_{t}^{H}+z_{t}^{g} r x_{t}^{H}\left(1-\frac{x_{t}^{H}}{K^{H}}\right)+m K^{H}\left(\frac{x_{t}^{R}}{K^{R}}-\frac{x_{t}^{H}}{K^{H}}\right)-h_{t} ; \text { and } \\
& x_{t+1}^{R}=x_{t}^{R}-z_{t}^{S} x_{t}^{R}+z_{t}^{g} r x_{t}^{R}\left(1-\frac{x_{t}^{R}}{K^{R}}\right)-m K^{H}\left(\frac{x_{t}^{R}}{K^{R}}-\frac{x_{t}^{H}}{K^{H}}\right)
\end{aligned}
$$

where the third term in the right hand side of the equations is the density dependent growth function with the carrying capacity, $K^{i}$, $i=H, R$, and the fourth term is the density dependent fish transfer

\footnotetext{
${ }^{7}$ The parameter regions for the optimal closure of patch $i$ can be derived by parameterizing the model and solving the system of non-linear Eqs. (4) and (5) for all $i$. This is, however, not the main focus of this paper. Using a deterministic dynamic optimization model, Sanchirico et al. (2006) find that the conditions for the optimal "no-take" zones depend on the spatial heterogeneity in harvesting costs and dispersal mechanisms. Moreover, Costello and Polasky (2008) shows that the fishing closure in patch $i$ is optimal if and only if the fish stock falls below the patch specific escapement target.

${ }^{8}$ An alternative assumption is to make the policy regime as a control variable such that both patches may be open or closed.
}

function where $m$ is the transfer coefficient. ${ }^{9}$ Assuming that each patch has the same carrying capacity, the transfer function can be reduced to $m\left(x_{t}^{R}-x_{t}^{H}\right)$.

The model incorporates two different types of uncertainties. The term $z_{t}^{g}$ represents stochastic variations in fish growth, and $z_{t}^{s}$ is a large negative shock. The growth uncertainty is specified as $z_{t}^{g}=1+\left(2 u_{t}-1\right) \varepsilon$, where $u_{t}$ is a uniformly discretized grid between 0 and 1 and follows a Markov chain with the same transition probabilities. The term $\varepsilon$ is a parameter that determines the size of variations. The large negative shock $z_{t}^{s}$ is specified as:

$z_{t}^{s}\left(\omega_{t}\right)=\omega_{t} \eta$

The size of the negative shock is proportional to the stock level and is determined by the parameter $\eta$. The variable $\omega_{t}$ is the indicator variable taking the value of either 0 or 1 . The negative shock is realized at time $t$ if $\omega_{t}=1$, but there is no shock if $\omega_{t}=0$. The realization of the negative shock follows a Markov chain with the transition matrix given by:

$\pi\left(\omega^{\prime} \mid \omega\right)=\operatorname{Pr}\left(\omega_{t+1}=\omega^{\prime} \mid \omega_{t}=\omega\right)=\left(\begin{array}{cc}1-\alpha & \alpha \\ 1 & 0\end{array}\right)$

where, for example, $\operatorname{Pr}\left(\omega_{t+1}=1 \mid \omega_{t}=0\right)=\alpha$ is the probability that the negative shock is realized. Given that the $\operatorname{Pr}\left(\omega_{t+1}=0 \mid \omega_{t}=1\right)=1$, the shock is not realized in consecutive periods.

The net profit from harvesting at time $t$ is specified as

$R_{t}=p\left(h_{t}\right) h_{t}-c\left(h_{t}, x_{t}^{H}\right)$

where $p(\cdot)$ is the inverse demand function and $c(\cdot)$ is the harvesting cost. The inverse demand and cost functions are specified respectively as:

$p(\cdot)=\bar{p} h_{t}^{-1 / \delta}$ and $c(\cdot)=\frac{\bar{c} h_{t}}{x_{t}^{H}}$

where $\delta$ is the constant price elasticity of demand, and $\bar{p}$ and $\bar{c}$ are parameters (Clark 1990).

We specify the functional form of the non-consumptive value as:

$N C\left(x_{t}\right)=\frac{b_{0}}{1+\exp \left(b_{1}-b_{2} x_{t} / K\right)}$

where $b_{0}, b_{1}, b_{2}>0$ are parameters. Eq. (11) is a logistic function where $x_{t}=x_{t}^{R}+x_{t}^{H}, K=K_{R}+K_{H}$ and $\mathrm{d} N C / \mathrm{d} x_{t}>0 .{ }^{10}$ The parameter $b_{0}$ represents the supremum value of $N C$. The parameters $b_{1}$ and $b_{2}$ determine the curvature of the non-consumptive value function. The greater (or smaller) the value of $b_{1}$ (or $b_{2}$ ) the smaller the non-consumptive value with a given value of $x_{t}$. Given this functional form, the nonconsumptive value of the fish stocks initially increases in a progressive way as $x_{t}$ rises, but the rate of increase diminishes when the value approaches its supremum value.

\footnotetext{
9 This functional form ensures that the relative size of the carrying capacity affects the dispersal pattern (Kramer and Chapman 1999). A density dependent transfer function is consistent with the finding in Abesamis and Russ (2005) and commonly utilized in previous studies, for example, Conrad (1999), Grafton et al. (2006) and also Bischi et al. (2009).

10 For non-timber benefits in forestry, Hartman (1976) uses a similar functional form where non-timber benefits are monotonically increasing, whereas Swallow et al. (1997) employ an alternative functional form where the non-timber benefits are diminishing once stands reach a certain age.
} 
In our model specification the regulator controls the harvest limit at the fishing ground as well as the location of the reserve. At each time $t$, the regulator decides whether or not to rotate the reserve from one patch to the other, i.e.,

$s_{t}=\left\{\begin{array}{l}0, \text { if remaining at the same patch } \\ 1, \text { if rotating the reserve. }\end{array}\right.$

We consider two optimization problems. The first is that the nonconsumptive value of the reserve is ignored and the regulator maximizes the harvesting value of the fishery only. Thus, the objective function is:

$\mathbb{E}_{0} \sum_{t=0}^{\infty} \beta^{t} R_{t}$

where $\mathbb{E}_{0}$ is the expectation conditional on information available at time 0 . In the second problem, the regulator maximizes the sum of the harvesting and non-consumptive values of the fishery and thus the objective function is:

$\mathbb{E}_{0} \sum_{t=0}^{\infty} \beta^{t}\left(R_{t}+N C_{t}\right)$

Both problems are subject to the biological constraint Eq. (6) and the initial conditions for $x_{t}^{H}, x_{t}^{R}, u_{t}$ and $\omega_{t}$. When comparing the results from these two problems, we can explicitly analyze whether and to what extent the non-consumptive value of the fishery affects the optimal reserve switching rule.

The Bellman equation for the optimization problem with the objective function given by Eq. (13) is:

$$
\begin{aligned}
V\left(x^{H}, x^{R}, s, u, \omega\right)= & \max _{h \in \Gamma, s \in\{0,1\}}\left\{R\left(h, x^{H}, 0\right)+\beta \mathbb{E}\left[V\left(x^{H^{\prime}}, x^{R^{\prime}}, 0, u^{\prime}, \omega^{\prime}\right) \mid u, \omega\right],\right. \\
& \left.R\left(h, x^{H}, 1\right)+\beta \mathbb{E}\left[V\left(x^{H^{\prime}}, x^{R^{\prime}}, 1, u^{\prime}, \omega^{\prime}\right) \mid u, \omega\right]\right\}
\end{aligned}
$$

where $\Gamma$ represents the set of all feasible harvest limits and $\mathbb{E}[\cdot \mid u, \omega]$ is the expectation conditional on the current values of $u$ and $\omega$. The value function $V(\cdot)$ represents the maximum attainable objective function. The first term on the right hand side of the equation, $R\left(h, x^{H}, 0\right)$, is the economic returns if the reserve remains at the current location $(s=0)$ and the following term, $\beta \mathbb{E}[\cdot]$, is the return from the next period onward. By contrast, the term $R\left(h, x^{H}, 1\right)$ is the economic returns if the reserve is rotated to the other patch $(s=1)$ and the following term, $\beta \mathbb{E}[\cdot]$, is the return for the following periods. Similarly, the Bellman equation for the optimization problem with the objective function given by Eq. (14) is:

$$
\begin{aligned}
V\left(x^{H}, x^{R}, s, u, \omega\right)= & \max _{h \in \Gamma, s \in\{0,1\}}\left\{R\left(h, x^{H}, 0\right)+N C(x, 0)\right. \\
& +\beta \mathbb{E}\left[V\left(x^{H^{\prime}}, x^{R^{\prime}}, 0, u^{\prime}, \omega^{\prime}\right) \mid u, \omega\right], R\left(h, x^{H}, 1\right) \\
& \left.+N C(x, 1)+\beta \mathbb{E}\left[V\left(x^{H^{\prime}}, x^{R^{\prime}}, 1, u^{\prime}, \omega^{\prime}\right) \mid u, \omega\right]\right\} .
\end{aligned}
$$

To obtain the optimal policy for $h$ and $s$ we first discretize the population states $\left(x^{H} \in X^{H} \equiv\left\{0, \ldots, K^{H}\right\}\right.$ and $\left.x^{R} \in X^{R} \equiv\left\{0, \ldots, K^{R}\right\}\right)$ and the growth uncertainty and negative shock $\left(u \in U \equiv\left\{u_{1}, \ldots, u_{m}\right\}\right.$ and $\omega \in \Omega \equiv\{0,1\}$ ). Using the value iteration method (Judd, 1998), the optimal harvest limit $\left(h^{*}\right)$ for given sizes of populations $\left(x^{H}\right.$ and $\left.x^{R}\right)$ and each realization of the growth uncertainty and negative shock ( $u$ and $\omega$ ) is computed. We calculated current economic returns corresponding to the optimal harvest limit when the reserve $i$ ) is rotated to the other patch and $i$ ) remains at the same patch, respectively, i.e., $R\left(h^{*}, x^{H}, 0\right)$ and $R\left(h^{*}, x^{H}, 1\right)$ or $R\left(h^{*}, x^{H}, 0\right)+N C(x, 0)$ and $R\left(h^{*}, x^{H}, 1\right)+N C(x, 1)$. Using the calculated current economic returns, the Bellman equation given in Eqs. (15) or (16) and the value iteration method, we computed the optimal switching rule function for given sizes of populations and each realization of the growth uncertainty and negative shock, i.e., $s^{*}=\phi\left(x^{H}, x^{R}, u, \omega\right)$ and $\phi: X^{H} \times X^{R} \times U \times \Omega \rightarrow\{0,1\}$. The tolerance for the convergence criterion in the value iteration is set to $\left\|V^{l}-V^{l}+{ }^{1}\right\|_{\infty}<1^{-10}$ where $l=\{1,2, \ldots\}$ is the number of iteration.

\section{Model Parameterization: The Red Throat Emperor Fishery}

The model is parameterized using data and coefficient estimates from the red throat emperor fishery in the Great Barrier Reef (GBR) of Queensland, Australia. The red throat emperor (Lethrinus miniatus) is one of the major targeted species for both the commercial and recreational sectors. The fishery is managed by setting the total allowable catch (TAC) with individual transferable quotas (ITQs) for the commercial catch and also by minimum legal size regulations (Leigh et al., 2006). An important feature of this fishery is that it operates entirely within the Great Barrier Reef World Heritage Area (GBRWHA) such that the park's regulator also imposes spatial management controls including temporary and permanently closures of the fishing grounds (Williams, 2003). The annual catch increased approximately four times between 1980 and 2003 while the catch per unit of effort dropped dramatically in the mid $1990 \mathrm{~s}$.

To simulate the model, the values for the biological parameters are obtained from Leigh et al. (2006). The intrinsic growth rate $(r)$ is 0.12 and the carrying capacity $(K)$ is 6913 metric tons. In the absence of sufficient data, the parameters in the price and cost functions and transfer coefficient are initially set at $\bar{p}=5, \delta=1.1, \bar{c}=5$ and $m=0.05$, but detailed sensitivity analysis of changes in these parameters is also undertaken. ${ }^{11}$ We specify the growth uncertainty as $\varepsilon=0.05$, the arrival rate of the negative shock as $\alpha=0.04$ and the size of the shock is set at $\eta=0.1$. The discount factor is initially set at $\beta=0.95$.

\subsection{Harvest and Biomass: Optimal Marine Reserve Switching versus Fixed Reserve}

Initially, we simulate the harvest and biomass associated with optimal marine reserve switching without accounting for nonconsumptive values. We then compare these results with those associated with a spatially fixed reserve regime. The density distribution of the average harvest and biomass at the steady-state is computed using Monte Carlo simulations. We apply the same realization of the growth uncertainty and negative shock for the two policy scenarios. The simulation involves 10,000 iterations of 100 periods of harvest and biomass and then use kernel density estimation to compute the probability density function.

Fig. 1 shows that the biomass is higher in the fixed reserve case. By contrast, the harvest is greater in the switching strategy. In the switching strategy, a fishing area is rotated to the previously closed area where fish stocks are relatively more abundant. As a result, the harvest in the switching strategy becomes greater than that in the fixed reserve case. At the same time, however, the increase in the harvest produces a smaller biomass in the switching strategy. Thus, by rotating a reserve optimally, the switching strategy generates a greater catch, but smaller biomass than the fixed reserve case.

The density distribution of the biomass and harvest when there are no fish spillovers $(m=0)$ from the reserve to harvest populations are compared in Fig. 2. An important function of a marine reserve is that the spillovers from the reserve to the harvested populations smooth the average biomass over the reserve and harvested areas. Thus, without a spillover effect from the reserve to harvested areas, the reserve no longer averages the biomass over the areas, and, as a result,

\footnotetext{
${ }^{11}$ While the landed price of red throat emperor has been relatively stable in the last two decades, a finite price elasticity of demand is necessary to satisfy the second-order conditions for a maximum.
} 

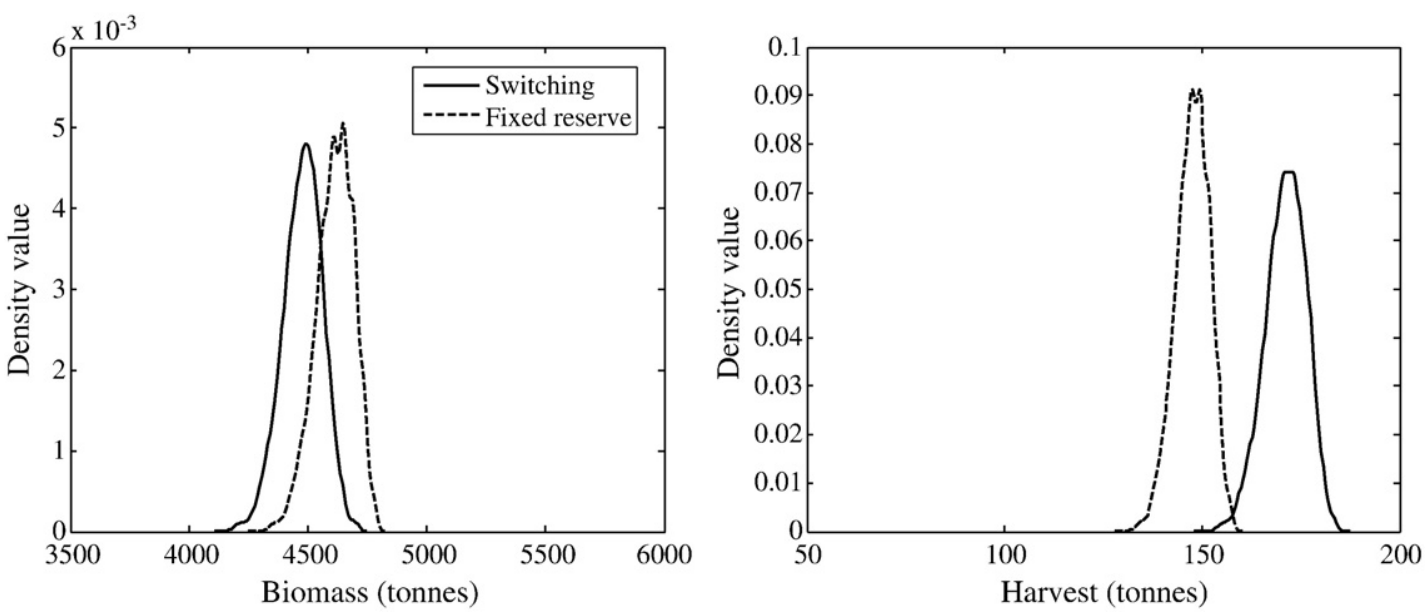

Fig. 1. Density distribution of biomass and harvest $(m=0.05)$.
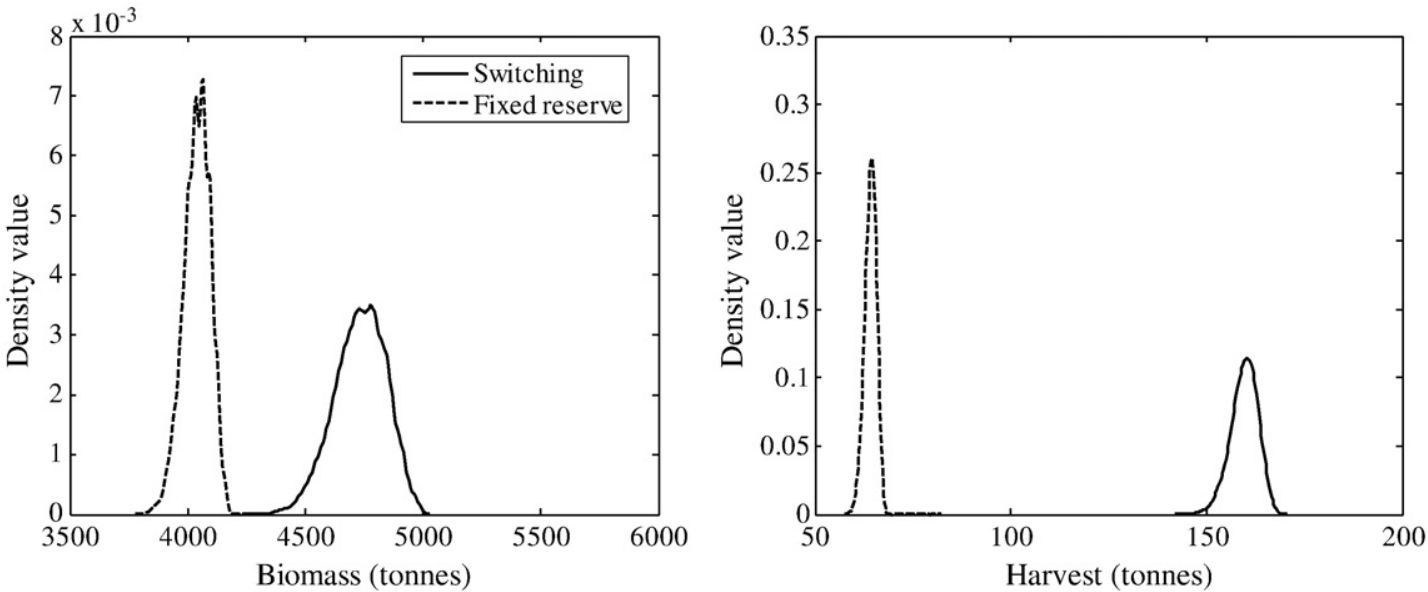

Fig. 2. Density distribution of biomass and harvest with no spillovers $(m=0)$.

the harvest and biomass in the fixed reserve case is lower than those in the reserve switching case. Further, without a reasonable volume of fish flow, the total exploitable population becomes significantly small in the fixed reserve case. In other words, when there are only weak linkages between patches, a large trade-off exists between the harvest and biomass with a spatially fixed reserve. However, the switching strategy can decrease the degree of this trade-off. By rotating a nonfishing area over time, the switching strategy maintains relatively high levels of both catch and fish stocks, even if there are only weak linkages between adjacent patches.

\subsection{Biological and Economic Parameters}

The difference in policy outcomes between the switching and fixed reserve regimes depends on the relative size of the biological and economic parameters. We analyze how the harvesting values in different policy scenarios changes with different values of the transfer coefficient $(m)$, harvesting cost $(c)$, price elasticity $(\delta)$, the time discount rate $(\rho)$, and the size of negative shocks $(\eta)$. We simulated the average harvesting value for each policy scenario at the steadystate for different values of the parameters and subsequently compute the difference in the average harvesting value between the two scenarios. The results are summarized in Table 1.

Table 1 shows that the greater is the transfer coefficient $(m)$, the smaller is the difference between the switching and fixed reserve cases. As shown in Fig. 2, the benefit of rotating a reserve depends critically on the fish transfer coefficient $(m)$. Without sufficient positive spillovers from the reserve to harvested populations, the fixed reserve decreases the total exploitable population and, in turn, the overall harvest.

The optimal switching rule depends on the profitability from harvesting fish stocks. Thus, the price-cost ratio and price elasticity of the demand, in part, determines the optimal switching interval of a "no-take" area. For instance, when the harvesting cost (c) increases or the price elasticity decreases, the net profit becomes more sensitive to the change in the fish stock and, consequently, the optimal switching interval becomes greater. In other words, as harvesting costs increase or the price elasticity decreases, the difference in the harvesting value between the switching and fixed reserve regimes becomes less. ${ }^{12}$

The smaller is the discount rate $(\rho)$, the larger is the discount factor and the greater is the marginal benefit of delaying the harvest to the next period. As a result, the optimal switching interval becomes greater and, in turn, the difference between the switching and fixed reserve cases becomes smaller when the discount rate is small.

In terms of the size of the negative shock $(\eta)$, Table 1 shows that the larger is the size of the negative shock $(\eta)$, the greater is the

\footnotetext{
12 It is important to note that the findings here are related to the optimal reserve size - the greater the harvesting cost the larger the optimal reserve size (Grafton et al., 2006). This is because, the higher the harvesting cost, the more sensitive the profitability of a fishery to a decline in the fish stock. Therefore, as the harvesting cost increases, the optimal size of a reserve is greater for stock recovery through the spillovers from the reserve to harvested populations.
} 
Table 1

Effect of marginal increase in parameter values on the difference in the harvesting value between switching and fixed reserve.

\begin{tabular}{lllll}
\hline $\begin{array}{l}\text { Transfer } \\
\text { coefficient }(m)\end{array}$ & $\begin{array}{l}\text { Cost } \\
\text { parameter }(c)\end{array}$ & $\begin{array}{l}\text { Price } \\
\text { elasticity }(\delta)\end{array}$ & $\begin{array}{l}\text { Discount rate } \\
(\rho)\end{array}$ & $\begin{array}{l}\text { Size of shock } \\
(\eta)\end{array}$ \\
\hline- & - & + & + & + \\
\hline
\end{tabular}

Note: $\mathrm{A}(+)$ indicates that a marginal increase in the given parameter value, holding everything else constant, will increase the difference in the harvesting value between the two management scenarios, while a $(-)$ indicates it will decrease the difference.

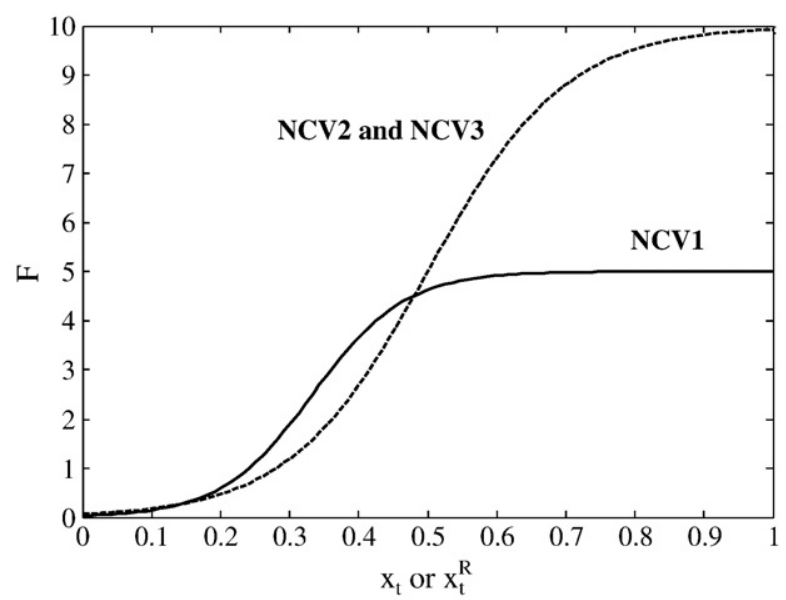

Notes:

1. NCV1 and NCV2 are functions of the aggregate population $\left(x_{t}=x_{t}^{R}+x_{t}^{H}\right)$. 2. NCV3 is a function of the reserve population $\left(x_{t}^{R}\right)$ only.

Fig. 3. Three types of non-consumptive value functions.

difference in the harvesting value between the switching and fixed reserve cases. In the switching strategy, once the harvested population declines significantly following a shock, the area is closed for stock recovery. In the meantime, the fishing ground is rotated to the previously closed area where the fish stock is more abundant. This benefit of rotating a reserve is greater when the size of the negative shock is large, and as a result, the difference between the switching and fixed reserve cases becomes greater.

\section{Non-consumptive Values and Marine Reserve Switching}

An issue unexplored in the economic literature, until now, is how the optimal switching rule changes after consideration is given to the

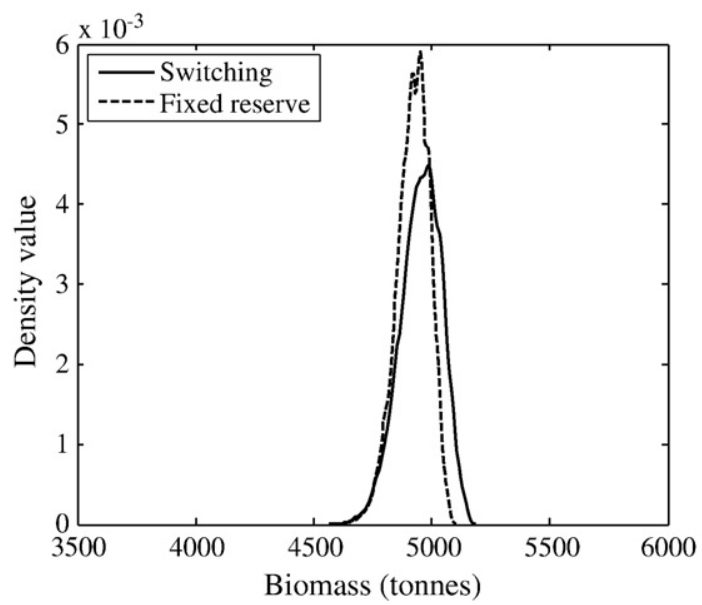

non-consumptive value of the fishery. In this case, the regulator's objective is to maximize the sum of the discounted net profit and nonconsumptive value rather than the net harvesting profit only. To investigate how the optimal switching rule and its policy outcomes change depending on different characteristics of the non-consumptive value of the fishery, we consider different types of nonconsumptive value functions that are illustrated in Fig. 3.

In the first type of the function (NCV1), the non-consumptive value of the fishery reaches the maximum value with a relatively small biomass. In the second type (NCV2), by contrast, the maximum value is greater than that with NCV1 and it requires a higher biomass to realize this maximum value. The third type (NCV3) arises only when a "no-take" area generates the non-consumptive value of the fishery, and thus the non-consumptive value function is specified as $F\left(x_{t}^{R}\right)=b_{0} /\left(1+\exp \left(b_{1}-b_{2} x_{t}^{R} / K^{R}\right)\right)$. This is a special case of NVC2 such that the regulator's objective is to protect the particular area for conservation.

\subsection{Harvest and Biomass}

Figs. 4 and 5 illustrate the density distribution of the biomass and harvest under the different non-consumptive value functions. When the non-consumptive value is taken into account, the value of maintaining the fish population is weighted more heavily. Consequently, the biomass in the switching strategy is now greater than that in the fixed reserve case, whereas the harvest difference between the two policy scenarios becomes smaller than the case in Fig. 1. In particular, the harvest in the switching strategy is less than the fixed reserve case if the maximum value of the non-consumptive value is relatively high and if it requires a higher biomass to realize the maximum value (such as with the NCV2 case). Therefore, rotating a reserve creates a trade-off between the harvesting and nonconsumptive values of the fishery.

Fig. 6 shows the density distribution of the biomass and harvest when only the reserve population generates the non-consumptive value of the fishery. The figure shows that there is no difference between the switching and fixed reserve cases. In other words, the trade-off between harvesting and non-consumptive values by rotating a reserve is too large and there is no extra benefit from rotating a reserve. This result is consistent with our intuition that when a reserve is created to protect a particular area or population, the re-exploitation of the area is less likely to generate extra economic payoffs.

\subsection{Optimal Frequency of Switching}

Table 2 illustrates the optimal frequency of switching in four different cases. To compute the optimal frequency, we use the simulated 10,000 time series of 100 periods of the indicator variable $s_{t}$

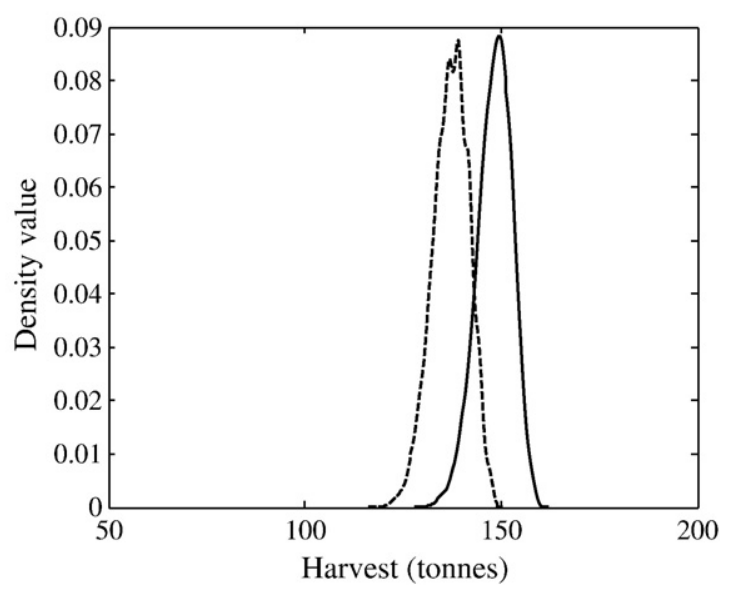

Fig. 4. Density distribution of biomass and harvest with non-consumptive values (NCV1) ( $m=0.05)$. 

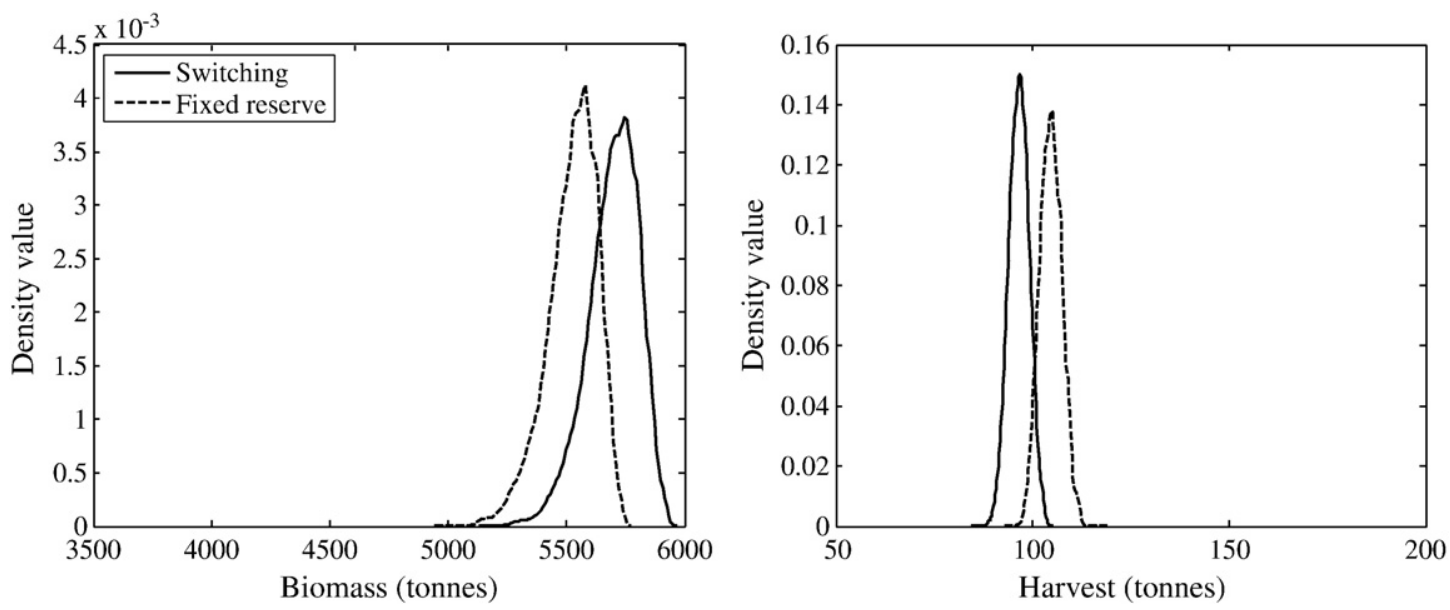

Fig. 5. Density distribution of biomass and harvest with non-consumptive values (NCV2) $(m=0.05)$.

and calculate the average switching occurrences. The table shows that, when the non-consumptive value of reserves is ignored, the reserve is, on average, rotated in $74.9 \%$ of periods (i.e., every 1.3 period). However, if the non-consumptive value of the fishery is included, the optimal frequency of switching is reduced. This is because, as shown in the marginal equilibrium condition (4), the marginal benefit of delaying the harvest to the next period is greater when accounting for the non-consumptive value.

Table 2 shows that, when the non-consumptive value is accounted for, the optimal switching frequency is the highest for the NCV1 case and the lowest for the NCV3 case. For the NCV1 case, the maximum non-consumptive value is relatively low and is realized with a smaller biomass than the other two cases, NCV2 and NCV3. Thus, the foregone non-consumptive benefit from rotating a reserve is less than the other two types. By contrast, for the NCV3 case, only the reserve population contributes to the non-consumptive value. Thus, the foregone nonconsumptive benefit from rotating the reserve is too large, and, as a result, the optimal switching frequency is zero.

\section{Concluding Remarks}

Marine reserves are receiving increased attention as a policy instrument to solve management failures in fisheries. Previous studies have found that under certain conditions reserves will provide a winwin solution, namely, both the biomass and harvest can be greater than without reserves in the presence of negative shocks. While this literature provides important insights into the design of optimal reserve management, until now, there has been no model to determine whether and when non-fishing areas should be rotated over time while accounting for non-consumptive values.

To address these crucial gaps in marine reserve design, a stochastic bioeconomic model is developed to analyze a marine reserve switching strategy while accounting for both harvesting and nonconsumptive values of a fishery. Parameterization of the model to the red throat emperor fishery in the Great Barrier Reef of Australia shows that an optimal switching strategy is to maintain a relatively high catch and biomass, if there are only weak linkages between the reserve and harvest populations. If sufficient spillovers from the reserve to harvested populations were not generated, fixing the nonfishing area at one site could substantially decrease the total harvest. When the transfer rate or spillovers across sites is small, a strong trade-off exists between the harvest level and the biomass in the fixed reserve case. In such cases, switching a reserve into a harvested area reduces this trade-off and can increase consumptive values.

A key contribution of the modeling is the finding that the optimal frequency of switching decreases if the non-consumptive values are accounted for in the decision process. Switching the reserve may still, however, be optimal with a reduced switching interval if the maximum non-consumptive value is relatively low and if this value is realized at a relatively small biomass. We further show that the larger the payoffs from non-consumptive activities and the more difficult or costly it is to realize the consumptive values, a reserve switching regime becomes less desirable relative to a fixed reserve regime.
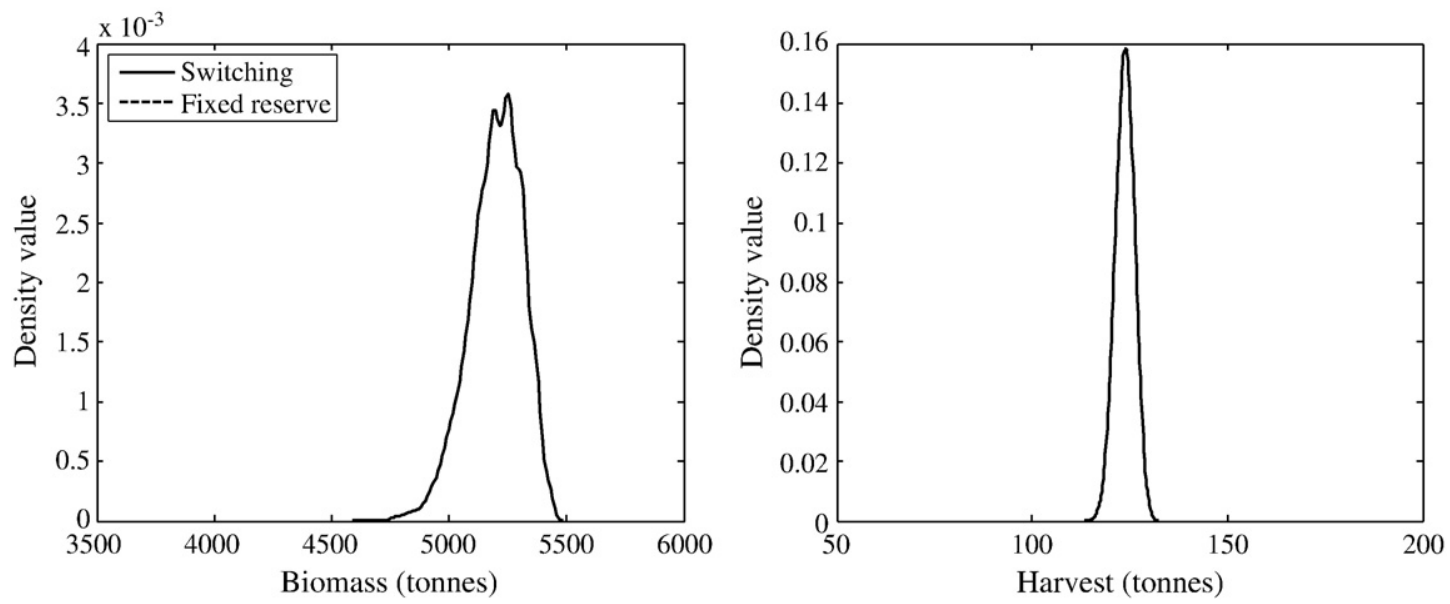

Fig. 6. Density distribution of biomass and harvest with non-consumptive values (NCV3) $(m=0.05)$. 
Table 2

Optimal frequency of switching.

\begin{tabular}{lllll}
\hline & Without non- & \multicolumn{3}{l}{ With non-consumptive value } \\
\cline { 3 - 5 } & consumptive value & NCV1 & NCV2 & NCV3 \\
\hline Mean & 0.749 & 0.649 & 0.555 & 0 \\
Max & 0.905 & 0.795 & 0.618 & 0 \\
Min & 0.617 & 0.548 & 0.453 & 0 \\
\hline
\end{tabular}

Note: These numbers were calculated using 10,000 Monte Carlo simulations. The numbers in the first row represent the average occurrence frequency of switching for 100 periods. The numbers in the second and third rows represent the maximum and minimum frequency.

Overall, the results show that under a wide range of scenarios it can be optimal to rotate a "no-take" area from one site to another, especially if the fish migration rate is low in the environment. An optimal switching strategy offers the possibility of maintaining both a high catch level and fish biomass, but it also requires detailed knowledge of the population dynamics, the nature of non-consumptive values and the environment coupled with appropriate monitoring and evaluation. Whether switching is optimal, however, is dependent on the spillovers from reserves to harvested areas, the nature of shocks to the environment, the size of the non-consumptive values and the sensitivity of profits to changes in harvest and biomass size.

\section{Acknowledgements}

We are grateful for the comments and suggestions from three anonymous reviewers. We also thank John Freebairn, Sturla Kvamsdal, Rich Little and Jack Pezzey for their helpful comments. This work was partially funded by the Australian Research Council and the Environmental Economics Hub, a Commonwealth Environmental Research Facility (CERF).

\section{References}

Abesamis, R.A., Russ, G.R., 2005. Density-dependent spillover from a marine reserve: long-term evidence. Ecological Applications 15, 1798-1812.

Allison, G.W., Lubchenco, J., Carr, M.H., 1998. Marine reserves are necessary but not sufficient marine conservation. Ecological Applications 8, S79-S92.

Bhat, M.G., 2003. Application of non-market valuation to the Florida Keys marine reserve management. Journal of Environmental Management 67, 315-325.

Bischi, G.I., Lamantia, F., Sbragia, L., 2009. Strategic interaction and imitation dynamics in patch differentiated exploitation of fisheries. Ecological Complexity 6, 353-362.

Carter, D.W., 2003. Protected areas in marine resource management: another look at the economic and research issues. Ocean and Coastal Management 46, 439-456.

Clark, C.W., 1990. Mathematical Bioeconomics: The Optimal Management of Renewable Resources. Wiley, New York.

Clark, C.W., Munro, G.R., 1975. The economics of fishing and modern capital theory: a simplified approach. Journal of Environmental Economics and Management 2, 92-106.
Conrad, J.M., 1999. The bioeconomics of marine sanctuaries. Journal of Bioeconomics 1, 205-217.

Costello, C., Polasky, S., 2004. Dynamic reserve site selection. Resource and Energy Economics 26, 157-174.

Costello, C., Polasky, S., 2008. Optimal harvesting of stochastic spatial resources. Journal of Environmental Economics and Management. 56, 1-18.

Grafton, R.Q., Kompas, T., Schneider, V., 2005. The bioeconomics of marine reserves: a selected review with policy implications. Journal of Bioeconomics 7, 161-178.

Grafton, R.Q., Kompas, T., Ha, P.V., 2006. The economic payoffs from marine reserves: resource rents in a stochastic environment. Economic Record 82, 469-480.

Guénette, S., Lauck, T., Clark, C.W., 1998. Marine reserves: from Beverton and Holt to the present. Reviews in Fish Biology and Fisheries 8, 251-272.

Halpern, B.S., 2003. The impact of marine reserves: do reserves work and does reserve size matter? Ecological Applications 13, S117-S137.

Hannesson, R., 1998. Marine reserves: what would they accomplish? Marine Resource Economics 13, 159-170.

Hartman, R., 1976. The harvesting decision when a standing forest has value. Economic Inquiry $14,52-58$.

Hilborn, R., Walters, C., 1992. Quantitative Fisheries Stock Assessment: Choice, Dynamics and Uncertainty. Kluwer Academic Publishers, Dordrecht.

Hilborn, R., Stokes, K., Maguire, J.J., Smith, T., Botsford, L.W., Mangel, M., Orensanz, J. Parma, A., Rice, J., Bell, J., Cochrane, K.L., Garcia, S., Hall, S.J., Kirkwood, G.P., Sainsbury, K., Stefansson, G., Walters, C., 2004. When can marine reserves improve fisheries management? Ocean and Coastal Management 47, 197-205.

Judd, K., 1998. Numerical Methods in Economics. MIT Press, Cambridge.

Kragt, M.E., Roebeling, P.C., Ruijs, A., 2009. Effects of Great Barrier Reef degradation on recreational reef-trip demand: a contingent behaviour approach. Australian Journal of Agricultural and Resource Economics 53, 213-229.

Kramer, D.L., Chapman, M.R., 1999. Implications of fish home range size and relocation for marine reserve function. Environmental Biology of Fishes 55, 65-79.

Lauck, T., Clark, C.W., Mangel, M., Munro, G., 1998. Implementing the precautionary principle in fisheries management through marine reserves. Ecological Applications 8, S72-S78.

Leigh, G.M., Willimans, A.J., Begg, G.A., Gribble, N.A., Whybird, O.J., 2006. Stock assessment of the Queensland and coast red throat emperor (lethrinus miniatus) fishery. The State of Queensland, Department of Primary Industries and Fisheries.

Mangel, M., 2000. Irreducible uncertainties, sustainable fisheries and marine reserves Evolutionary Ecological Research 2, 547-557.

McClanahan, T.R., Mangi, S., 2000. Spillover of exploitable fishes from a marine park and its effect on the adjacent fishery. Ecological Applications 10, 1792-1805.

Pezzey, J.C.V., Roberts, C.M., Urdal, B.T., 2000. A simple bioeconomic model of a marine reserve. Ecological Economics 33, 77-91.

Roberts, C.M., Bohnsack, J.A., Gell, F., Hawkins, J.P., Goodridge, R., 2001. Effects of marine reserves on adjacent fisheries. Science $294,1920-1923$.

Sanchirico, J.N., Malvadkar, U., Hastings, A., Wilen, J.E., 2006. When are no-take zones an economically optimal fishery management strategy? Ecological Applications 16 1643-1659.

Swallow, S.K., Talukdar, P., Wear, D.N., 1997. Spatial and temporal specialization in forest ecosystem management under sole ownership. American Journal of Agricultural Economics 79, 311-326.

White, C., Kendall, B.E., Gaines, S., Siegel, D.A., Costello, C., 2008. Marine reserves effects on fishery profit. Ecological Letters 11, 370-379.

Wielgus, J., Sala, E., Gerber, L.R., 2008. Assessing the ecological and economic benefits of a no-take marine reserve. Ecological Economics 67, 32-40.

Williams, L.E., 2003. Queensland's fisheries resources: current conditions and recent trends 1988-2000. The State of Queensland, Department of Primary Industries and Fisheries.

Worm, B., Barbier, E.B., Beaumont, N., Duffy, J.E., Folke, C., Halpern, B.S., Jackson, J.B.C. Lotze, H.K., Michelo, F., Pakumbi, S.R., Sala, E., Selkoe, K.A., Stachowicz, J.J., Watson, R., 2006. Impacts of biodiversity loss on ocean ecosystem services. Science 314, 787-790. 